\title{
Variation in Competitive Ability Among Isolates of Aspergillus flavus from Different Vegetative Compatibility Groups During Maize Infection
}

\author{
H. L. Mehl and P. J. Cotty
}

U.S. Department of Agriculture-Agricultural Research Service, School of Plant Sciences, The University of Arizona, P.O. Box 210036, Tucson 85721-0036.

Accepted for publication 5 October 2009.

\begin{abstract}
Mehl, H. L., and Cotty, P. J. 2010. Variation in competitive ability among isolates of Aspergillus flavus from different vegetative compatibility groups during maize infection. Phytopathology 100:150-159.

Aspergillus flavus, the primary causal agent of aflatoxin contamination, includes many genetically diverse vegetative compatibility groups (VCGs). Competitive ability during infection of living maize kernels was quantified for isolates from 38 VCGs. Kernels were inoculated with both a common VCG, CG136, and another VCG; after 7 days $\left(31^{\circ} \mathrm{C}\right)$, conidia were washed from kernels, and aflatoxins and DNA were extracted from kernels and conidia separately. CG136-specific single-nucleotide polymorphisms were quantified by pyrosequencing; VCGs co-inoculated with CG136 produced 46 to 85 and 51 to $84 \%$ of A. flavus DNA from kernels

and conidia, respectively. Co-inoculation with atoxigenic isolates reduced aflatoxin up to $90 \%$ and, in some cases, more than predicted by competitive exclusion alone. Conidia contained up to $42 \mathrm{ppm}$ aflatoxin $\mathrm{B}_{1}$, indicating airborne conidia as potentially important sources of environmental exposure. Aflatoxin-producing potential and sporulation were negatively correlated. For some VCGs, sporulation during co-infection was greater than that predicted by kernel infection, suggesting that some VCGs increase dispersal while sacrificing competitive ability during host tissue colonization. The results indicate both life strategy and adaptive differences among A. flavus isolates and provide a basis for selection of biocontrol strains with improved competitive ability, sporulation, and aflatoxin reduction on target hosts.
\end{abstract}

Aflatoxins, potent and carcinogenic mycotoxins produced by fungi in Aspergillus section Flavi, are frequent contaminants of food and feed crops. Aspergillus flavus is the most commonly isolated causal agent of aflatoxin contamination $(5,54)$ of many crops, including maize, cotton, peanut, and tree nuts (21). Levels of aflatoxins in food and feed crops are strictly regulated in many countries $(53,58)$; thus, aflatoxins can cause reduced crop value due to loss of premium markets. In the United States, for example, crops for human consumption cannot exceed $20 \mathrm{ppb}$ of total aflatoxin (48) but certain crop components may contain more than $10^{6} \mathrm{ppb}$ (38). Frequency and severity of contamination are influenced by both climate and the composition of resident $A$. flavus communities $(1,18,34)$.

Individual A. flavus isolates vary in many characteristics, including aflatoxin-producing ability, production and morphology of sclerotia, and sporulation $(10,54)$. Groups of A. flavus designated as the L, S, and T strains are separated based on sclerotial morphology and colony characteristics (10); these groups are further subdivided into vegetative compatibility groups (VCGs) by a heterokaryon incompatibility system. VCGs are typically identified by complementation of nitrate nonutilizing auxotrophs, and members of the same VCG are considered to be members of the same clonal lineage $(40,47)$; sequence data confirm that isolates within a VCG are closely related and distinct from other VCGs $(25,28)$. Phenotypic characteristics (i.e., size of sclerotia and aflatoxin-producing ability) are usually conserved within VCGs $(5,33,44,49)$.

Corresponding author: P. J. Cotty; E-mail address: pjcotty@email.arizona.edu

doi:10.1094/PHYTO-100-2-0150

This article is in the public domain and not copyrightable. It may be freely reprinted with customary crediting of the source. The American Phytopathological Society, 2010.
A. flavus communities in soils and on crops are composed of many VCGs $(4,31,49)$, with multiple VCGs occurring even in small components (i.e., 25-g aliquots of soil or individual cotton locules) (4). Frequencies of strains and VCGs vary among fields and crops $(1,4,13,22,30,49)$, and some VCGs are frequently isolated whereas others are rare $(4,31,49)$. Even though $A$. flavus apparently does not have host specificity (57), distributions of different A. flavus lineages suggest that they may be adapted to specialized niches and exhibit competitive advantages in specific soils, hosts, regions, and seasons $(7,30,35,46)$. In addition, variability in pectinase production among A. flavus isolates confers differential ability to utilize substrates $(9,17)$ and variation in virulence to plants (10).

Because both individual isolates and communities of $A$. flavus vary in both virulence and aflatoxin-producing potential $(10,13$, $27,30,54)$, strain frequency is an important determinant of crop aflatoxin content $(1,13,34,52)$. An increase in the frequency of low aflatoxin producers in the A. flavus community results in lower concentrations of aflatoxin in crops (19). The best demonstration of this is competitive exclusion of aflatoxin producers by atoxigenic isolates, a form of biocontrol that is used commercially to limit contamination in maize, cottonseed, pistachios, and peanut $(14,23)$. Atoxigenic A. flavus isolates compete with aflatoxin producers and reduce crop aflatoxin content by lowering the average aflatoxin-producing potential of crop-associated fungal communities (12). Although intraspecific competition is used to reduce contamination, variation among genetically diverse $A$. flavus in competitive ability has not been quantified. The current study sought to develop pyrosequencing assays to quantify competitive ability among A. flavus isolates belonging to 38 VCGs during infection of living maize kernels and to assess influences of competitive interactions on the extent to which maize becomes contaminated with aflatoxins. 


\section{MATERIALS AND METHODS}

Fungal isolates and cultures. The VCG, origin, and single nucleotide polymorphisms (SNPs) for isolates used in this study are described in Table 1. For simplicity, each isolate will be referred to by the VCG to which it belongs and, in this study, a VCG refers to a single isolate. Nitrate nonutilizing auxotrophs $\left(\mathrm{niaD}^{-}\right)$were used in this study both so that VCGs could be confirmed rapidly by complementation with tester mutants of the same VCG and to ensure that cultures consisted of a single genetic type. Isolates were grown from silica gel storage on $5 / 2$ agar (5\% V8 juice, $2 \%$ agar, $\mathrm{pH} 5.2)$ and conidial suspensions from plugs of mature cultures were maintained in vials (4-ml) containing sterile distilled water. Conidial suspensions from water vials were used to centrally seed plates of $5 / 2$ agar for inoculum production.

Maize inoculations. Unbroken uniform-sized kernels ( $5 \mathrm{~g}$ ) of grain from Pioneer hybrid 33B50 were disinfected by submersion in $80^{\circ} \mathrm{C}$ water for $45 \mathrm{~s}$ and added to $250-\mathrm{ml}$ Erlenmeyer flasks that were subsequently sealed with gas-permeable BugStopper plugs (Whatman, Piscataway, NJ). A subsample of disinfected kernels was plated on agar to confirm viability and lack of contaminating fungi. To quantify competitive ability, one isolate from each of 38 different VCGs was co-inoculated with an isolate from VCG CG136 (Table 1). Kernels inoculated with either CG136 alone or sterile water alone were included as positive and negative controls. Conidia of 7-day-old cultures were dislodged with sterile cotton swabs and suspended in $0.1 \%$ Tween- 80 . Suspensions were adjusted to 50,000 conidia in half the appropriate volume of water to bring total moisture of inoculated maize kernels to 25\% (see below). Kernels were first inoculated with an isolate from 1 of the 38 VCGs by gently shaking (10 s) the kernels after the conidial suspension was added and, after $1 \mathrm{~h}$, a conidial suspension of CG136 was similarly added to each flask. In a second experiment, kernels were inoculated with each isolate individually. After 7 days $\left(31^{\circ} \mathrm{C}\right)$, inoculated kernels were dried $\left(60^{\circ} \mathrm{C}, 48 \mathrm{~h}\right)$, conidia were washed from kernel surfaces with $0.1 \%$ Tween-80, turbidity was quantified (Model: Turbidometer; Orbeco Analytical Systems, Farmingdale, NY), and the quantity of conidia was estimated with a turbidity versus CFU standard curve. Aflatoxin and DNA were extracted independently from conidia and maize kernels as below. The co-inoculation and single inoculation experiments had four and three replicates per treatment, respectively, and each experiment was performed twice. Treatments were arranged in a randomized complete block design.

Aflatoxin extraction and quantification. Maize kernels were pulverized for $10 \mathrm{~s}$ in an analytical mill (IKA Works, Wilmington, $\mathrm{NC})$. Ground kernel ( $\approx 1.5 \mathrm{~g})$ was combined with $15 \mathrm{ml}$ of $85 \%$ acetone in a 22-ml glass vial with Teflon septum. Vials were periodically inverted for $1 \mathrm{~h}$, and sample extracts were separated alongside aflatoxin standards on thin-layer chromatography

TABLE 1. Isolates used in this study and the single nucleotide polymorphisms (SNPs) used to distinguish vegetative compatibility groups (VCGs) from VCG CG136 with pyrosequencing

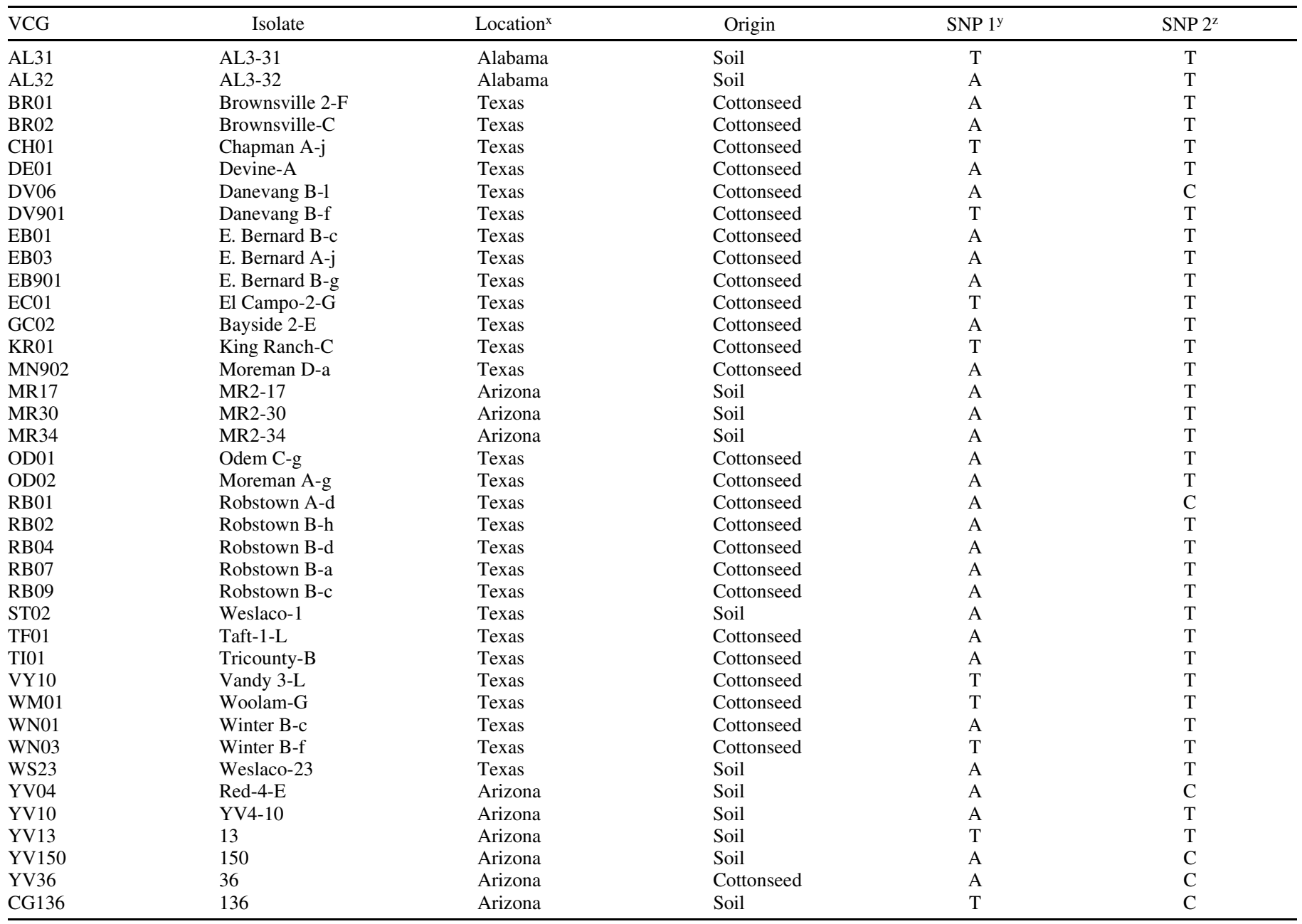

${ }^{\mathrm{x}}$ Location is the state where the isolate was collected.

${ }^{y}$ SNP 1 is located in a portion of the aflatoxin biosynthesis gene cluster.

${ }^{z}$ SNP 2 is located in a portion of the calmodulin gene. 
(TLC) plates (silica gelG, $250 \mu \mathrm{m}$ ) with $\mathrm{H}_{2} \mathrm{O}: \mathrm{MeOH}$ :ether (1:3:96). Aflatoxins were quantified directly on TLC plates by scanning fluorescence densitometry (50). Samples that were negative in the initial analysis were diluted with an equal volume of water and extracted twice with $5 \mathrm{ml}$ of methylene chloride. Extracts were combined and dried, and residues were dissolved in sufficient methylene chloride to allow accurate densitometry. Half of the conidia were used for DNA isolation, half were dried $\left(60^{\circ} \mathrm{C}, 24 \mathrm{~h}\right)$ and weighed, and aflatoxins were extracted with $2.5 \mathrm{ml}$ of $85 \%$ acetone and quantified as above. Samples initially negative for aflatoxins were evaporated to dryness and dissolved in sufficient methylene chloride to allow accurate densitometry. The limit of detection was $20 \mathrm{ppb}$ for kernels and $200 \mathrm{ppb}$ for conidia. Isolates for which aflatoxin $\mathrm{B}_{1}$ was not detected were considered atoxigenic for the purposes of this study.

DNA isolation. DNA was isolated from $200 \mathrm{mg}$ of pulverized kernel and half the conidia using the FastDNA SPIN Kit and the FastPrep Instrument (MP Biomedicals, Santa Ana, CA). Kernel and conidia DNA were diluted 1:10 and 1:100, respectively, with sterile purified water prior to polymerase chain reaction (PCR).

PCR and pyrosequencing. A pyrosequencing assay was developed to quantify proportions of conidia and kernel-infecting hyphae belonging to the CG136 isolate. Sequences of an intergenic region in the aflatoxin biosynthesis gene cluster (Afl) and the calmodulin gene (Cmd) were aligned for all isolates used in this study (Table 1), and CG136-specific SNPs were identified. PCR and sequencing primers were designed using PSQ Assay Design Software (Qiagen, Valencia, CA). The primer pairs CG136-Afl-F (5'-TGGCAGCCTTTCCAATTTA-3')/CG136-AflR (5'-TGAATCCCTCCCTGGATG-3') and CG136-Cmd-F (5'AGTTATCGTCGTTCGTGAAAATTG-3')/CG136-Cmd-R (5'TGGATAAAATTATGGCGGCTAAAA-3') amplified portions of DNA containing the CG136-specific SNPs. Primers CG136-Afl-F and CG136-Cmd-R were 5' biotinylated and high-performance liquid chromatography purified. A total reaction volume of $50 \mu \mathrm{l}$ contained 1× PCR Buffer II (Applied Biosystems, Foster City, CA), $2.5 \mathrm{mM} \mathrm{MgCl}_{2}, 0.2 \mathrm{mM}$ dNTP mix, $0.2 \mu \mathrm{M}$ each forward and reverse primers, 1.25 units of AmpliTaq Gold DNA Polymerase (Applied Biosystems), and $10 \mu \mathrm{l}$ of template DNA. Reaction conditions were $95^{\circ} \mathrm{C}$ for $5 \mathrm{~min}$; followed by 45 cycles of $95^{\circ} \mathrm{C}$ for $15 \mathrm{~s}, 56^{\circ} \mathrm{C}$ (Afl primers) or $53^{\circ} \mathrm{C}$ (Cmd primers) for $30 \mathrm{~s}$, and $72^{\circ} \mathrm{C}$ for $15 \mathrm{~s}$. A large number of cycles was used in order to fully consume the biotinylated primers so that they would not interfere with the pyrosequencing reaction. The final extension was at $72^{\circ} \mathrm{C}$ for $10 \mathrm{~min}$. Amplicons $(5 \mu \mathrm{l})$ were loaded on a $1 \%$ agarose gel in $1 \times$ Tris-borate-EDTA buffer, separated for $45 \mathrm{~min}$ at $100 \mathrm{~V}$, stained with SYBR gold, and visualized under ultraviolet light in order to confirm amplicons of 233 and $174 \mathrm{bp}$ for DNA amplified with CG136-Afl and CG136-Cmd primers, respectively.

Amplicons were prepared for pyrosequencing analysis using the Vacuum Prep Tool (Qiagen) as described previously (20) and according to the manufacturer's instructions. Briefly, biotinylated PCR products $(40 \mu \mathrm{l})$ were bound to streptavidin-coated beads, captured on the Vacuum Prep Tool filter probes, washed with 70\% ethanol, denatured to single-stranded DNA with $0.2 \mathrm{M} \mathrm{NaOH}$, and washed with buffer (10 mM Tris-Acetate, $\mathrm{pH}$ 7.6). The beadbound single-stranded PCR products were then released into a PSQ 96 sequencing plate (Qiagen) containing sequencing primer $(0.5 \mu \mathrm{M})$. Sequencing primer was hybridized to the singlestranded DNA by heating the plate to $90^{\circ} \mathrm{C}$ for $10 \mathrm{~min}$ and then cooling. Sequencing primers used for CG136-Afl and CG136Cmd assays were CG136-Afl-S2 (5'-AAGGATCATTACCTTG$\left.3^{\prime}\right)$ and CG136-Cmd-S (5'-CTATAGGACAAGGACGG-3'), respectively.

Pyrosequencing was performed with the PSQ 96MA pyrosequencer according to the manufacturer's instructions (Qiagen). The basic principal of pyrosequencing is that dNTPs are added sequentially, and the pyrosequencing reaction produces light that is proportional to the quantity of nucleotides incorporated into the DNA strand. The intensity of the light signal is detected as a peak on a Pyrogram, and peak heights are used to calculate relative quantities of each nucleotide at each target location. Relative quantities of VCG CG136 DNA were calculated using the allele quantification option of the PSQ 96MA 2.1 software.

Data analysis. Quantities of conidia and aflatoxin $\mathrm{B}_{1}$ were $\log$ transformed and percentage data were arcsine transformed prior to analysis. Data were combined across trials and analyzed as a mixed model using the SAS procedure GLIMMIX. The factors trial, block, and the interaction of trial $\times$ VCG were treated as random effects while VCG was treated as a fixed effect. Means from the combined trials were separated using Tukey-Kramer groupings for least square means. Correlations between dependent variables were performed between experiments on treatment means and within experiments on replicate values. For coinoculations, expected and observed relative concentrations of aflatoxin $B_{1}$ were calculated using values from the single VCG inoculation experiment and co-inoculation experiment, respectively. Expected values were calculated by multiplying the concentration of aflatoxin produced by VCG CG136 and the second VCG by their respective percentages as determined by pyrosequencing in the co-inoculation experiment and summing these values. Values for each replicate were calculated independently, and expected and observed values were compared using student's $t$ test. For atoxigenic VCGs, percent displacement of CG136 and percent aflatoxin reduction were compared using a paired $t$ test. When multiple $t$ tests were performed, $P$ values were adjusted using Bonferroni criterion. Statistical analyses were performed with SAS 9.1 (SAS Institute, Cary, NC).

\section{RESULTS}

Competition during co-infection. VCGs differed significantly in competitive ability $(P<0.0001)$, with CG136 comprising $15.4 \pm 2.2$ to $54.3 \pm 2.5 \%$ of A. flavus DNA in infected kernels (Fig. 1). The least and most competitive VCGs retained similar rankings in both trials. VCGs ranked 1 (EB01), 2 (YV10), and 3 (WM01) in the first trial were ranked 2, 3, and 7 in the second trial. The three least-competitive (MR17, DV901, and YV13) were ranked 38 and 38, 37 and 37, and 36 and 35 in the two trials.

Sporulation during competition. CG136 comprised $16.4 \pm$ 2.0 to $48.9 \pm 4.6 \%$ of DNA from conidia produced on infected kernels. The VCGs that contributed the largest percentage of conidia during competition with CG136 (GC02, DV06, and YV150) were ranked 5 and 1, 4 and 2, and 1 and 5 in the first and second trials, respectively; VCGs that produced the smallest percentage of conidia (RB04, YV13, and MR17) were ranked 38 and 32,34 and 38 , and 36 and 36 . There were significant differences among VCG pairs in total sporulation $(P=0.0002)$ (Table 2). Conidia production was significantly different among co-infecting VCGs (Table $2, P<0.0003$ ) and was only weakly correlated with the mean number of conidia produced when kernels were inoculated with the individual VCGs (Table 3). Quantities of conidia produced by CG136 were lower when it was co-inoculated with another VCG than when it was inoculated alone, and VCGs varied significantly in the extent to which they reduced sporulation by CG136 $(P<0.0001)$ (Table 2$)$. However, sporulation by CG136 was not significantly correlated with sporulation by the co-infecting VCG (Table 3).

Relationship between kernel infection and sporulation. In co-inoculated kernels, the proportion of infecting hyphae attributable to CG136 was a poor predictor of the proportion of conidia attributable to CG136. This relationship only explained 33 and $21 \%$ of the variation in conidial proportions in the first and second trials, respectively (Fig. 2). Although the correlation describing this relationship was highly significant $(P<0.0001)$, 
conidial and kernel proportions differed significantly for eight VCGs (Fig. 3) (paired $t$ test, Bonferroni adjusted $P<0.0013$ ). Four VCGs reduced CG136 kernel infection more than they reduced sporulation, and four VCGs reduced sporulation more than kernel infection.

Relationship between competitive ability and aflatoxin production. Concentrations and total quantities of aflatoxin $\mathrm{B}_{1}$ produced by each of the toxigenic VCGs growing individually on maize kernels are presented in Table 4 . Aflatoxin $\mathrm{B}_{1}$ concentrations were significantly different among VCGs in both infected maize kernels $(P<0.0001)$ and in conidia produced on kernels $(P<0.0001)$. Aflatoxin $\mathrm{B}_{1}$ concentrations in conidia were lower than in kernels but the two concentrations were highly correlated (Table 3). The mean aflatoxin content of conidia was $20 \pm$ $2 \%$ (range $=4$ to $36 \%$ ) of the concentration in kernels. However, the total quantity of aflatoxin contributed by conidia was only $<0.1$ to $3.3 \%$ of the total aflatoxin $B_{1}$ associated with infected kernels.

The aflatoxin-producing potential of a VCG grown individually on maize was not correlated with competitive ability as measured by the percent CG136 DNA in co-infected kernels (Table 3). However, there was a weak but significant inverse correlation between aflatoxin-producing potential and both the proportion and total quantity of conidia produced during co-infection (Table $3)$. Sporulation of single VCGs was not correlated with aflatoxinproducing ability (Table 3 ). Overall, atoxigenic VCGs contributed a greater proportion of conidia than aflatoxin producers $(73 \pm 1$ versus $66 \pm 0.8 \%$ of the total conidia; student's $t$ test, $P<0.0001$ ) during co-infection. The 6 VCGs that produced the largest proportions of conidia were atoxigenic, and 7 of the $10 \mathrm{VCG}$ that produced the smallest proportions of conidia were aflatoxin producers.

As expected, the aflatoxin content of maize inoculated with one VCG was correlated with the aflatoxin content of both kernels and conidia from maize kernels co-infected with that VCG and CG136 (Table 3). However, the combination of competitive ability and aflatoxin-producing potential (from single VCG inoculations) was not a reliable predictor of aflatoxin in coinfected kernels (Table 5). Eight VCGs produced significantly lower aflatoxin $\mathrm{B}_{1}$ in co-infected kernels than was predicted by multiplying the percent infecting hyphae by aflatoxin produced during single VCG inoculations (student's $t$ test, $P<0.05$ ). VCG BR02 was ranked higher than CG136 for aflatoxin production but, when co-inoculated with CG136, aflatoxin concentrations in the kernels were reduced $31 \%$ compared with kernels infected with CG136 alone. VCGs that produced less aflatoxin than CG136 were predicted to lower aflatoxin concentrations during co-infection but, for 15 and 19 out of 22 VCGs for kernels and conidia, respectively, the actual aflatoxin concentrations were lower than predicted based on aflatoxin-producing ability and percent displacement of CG136; 14 VCGs were significantly lower for either kernels, conidia, or both (Table 5). None of the kernels or conidia from co-inoculated treatments had significantly more aflatoxin than expected.

Relationship between displacement of VCG CG136 and aflatoxin reduction by atoxigenic VCGs. Atoxigenic VCGs varied in ability to both reduce aflatoxin $(P<0.0001)$ and displace CG136 $(P=0.003)$ during infection of maize kernels (Table 6). The quantity of aflatoxin $\mathrm{B}_{1}$ in conidia from co-infected kernels was significantly different among atoxigenic VCGs $(P=$

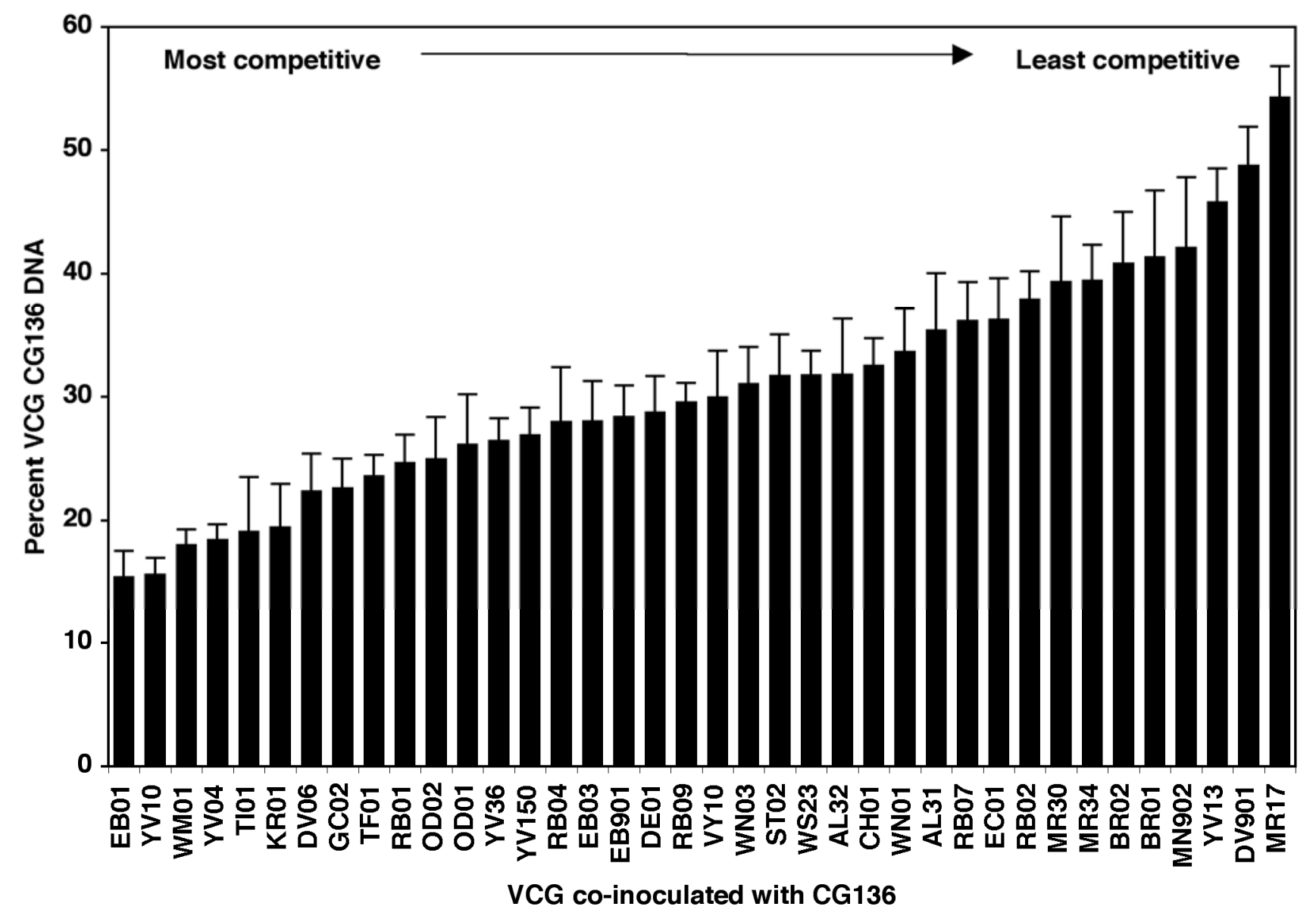

Fig. 1. Competitive ability of different Aspergillus flavus vegetative compatibility group (VCG) isolates co-infecting living maize kernels with VCG CG136. The percent of total A. flavus DNA that is composed of CG136 DNA is inversely proportional to the competitive ability of the co-infecting VCG. Combined data from two independent trials are shown. Error bars indicate one standard error. 
0.02) but mean separations were not detected (Table 6). The percentage of CG136 conidia produced during co-infection varied among atoxigenic isolates $(P=0.0009)$. There was a weak correlation between percent displacement of CG136 and percent aflatoxin reduction (kernels: $r^{2}=0.24, P<0.0001$; conidia: $r^{2}=$ $0.14, P<0.0001)$. Six of the VCGs had significantly higher levels of aflatoxin reduction than would be predicted by displacement of CG136 in the kernels, and three VCGs had less aflatoxin in conidia than would be predicted (Table 6).

\section{DISCUSSION}

This is the first study to quantitatively compare competitive abilities of genetically diverse A. flavus during infection of a living host. Pyrosequencing allowed highly precise (standard deviation $[\mathrm{SD}]<1 \%$ ) quantification of competitiveness during maize co-infection. Living kernels were co-inoculated with equal

TABLE 2. Quantities of conidia produced by vegetative compatibility group (VCG) CG136, the co-infecting VCG, and the two VCGs combined on maize kernels infected with either CG136 alone or CG136 and another VCG

\begin{tabular}{|c|c|c|c|}
\hline \multirow[b]{2}{*}{ Co-inoculated $\mathrm{VCG}^{\mathrm{y}}$} & \multicolumn{3}{|c|}{ No. of conidia $\left(\times 10^{9}\right)^{\mathrm{z}}$} \\
\hline & VCG CG136 & Co-infecting VCG & Total \\
\hline CG136 alone & $3.6 \mathrm{~A}$ & $3.6 \mathrm{ABC}$ & \\
\hline YV13 & $1.8 \mathrm{AB}$ & $1.9 \mathrm{ABC}$ & $3.7 \mathrm{AB}$ \\
\hline BR01 & $1.5 \mathrm{ABC}$ & $1.7 \mathrm{ABC}$ & $3.2 \mathrm{ABC}$ \\
\hline MR17 & $1.5 \mathrm{BC}$ & $1.7 \mathrm{ABC}$ & $3.2 \mathrm{ABC}$ \\
\hline RB04 & $1.5 \mathrm{BCD}$ & 1.7 ABC & $3.2 \mathrm{ABC}$ \\
\hline BR02 & 1.3 BCDE & $1.8 \mathrm{ABC}$ & $3.0 \mathrm{ABC}$ \\
\hline ST02 & 1.2 BCDE & $3.1 \mathrm{~A}$ & $4.3 \mathrm{~A}$ \\
\hline WN03 & 1.2 BCDEF & $3.0 \mathrm{AB}$ & $4.2 \mathrm{AB}$ \\
\hline EC01 & 1.2 BCDEF & $2.4 \mathrm{ABC}$ & $3.6 \mathrm{ABC}$ \\
\hline RB02 & 1.2 BCDEF & $2.1 \mathrm{ABC}$ & $3.3 \mathrm{ABC}$ \\
\hline KR01 & 1.2 BCDEF & $2.5 \mathrm{AB}$ & $3.7 \mathrm{ABC}$ \\
\hline TF01 & 1.2 BCDEF & $1.9 \mathrm{ABC}$ & $3.1 \mathrm{ABC}$ \\
\hline OD01 & 1.1 BCDEF & $2.3 \mathrm{ABC}$ & $3.4 \mathrm{ABC}$ \\
\hline WS 23 & 1.1 BCDEF & $2.0 \mathrm{ABC}$ & $3.1 \mathrm{ABC}$ \\
\hline MR30 & 1.1 BCDEF & $1.6 \mathrm{ABC}$ & $2.7 \mathrm{ABC}$ \\
\hline OD02 & 1.1 BCDEFG & $2.1 \mathrm{ABC}$ & $3.2 \mathrm{ABC}$ \\
\hline WM01 & 0.9 BCDEFGH & $2.3 \mathrm{ABC}$ & $3.3 \mathrm{ABC}$ \\
\hline MR34 & 0.9 BCDEFGH & 1.5 BCD & $2.4 \mathrm{BC}$ \\
\hline DV901 & 0.9 BCDEFGH & $1.3 \mathrm{C}$ & $2.2 \mathrm{C}$ \\
\hline DE01 & $0.9 \mathrm{BCDEFGH}$ & $2.5 \mathrm{AB}$ & $3.3 \mathrm{ABC}$ \\
\hline RB07 & 0.8 BCDEFGH & $1.9 \mathrm{ABC}$ & $2.7 \mathrm{ABC}$ \\
\hline AL31 & $0.8 \mathrm{CDEFGH}$ & $2.8 \mathrm{AB}$ & $3.6 \mathrm{ABC}$ \\
\hline TI01 & $0.8 \mathrm{CDEFGH}$ & $1.8 \mathrm{ABC}$ & $2.6 \mathrm{ABC}$ \\
\hline YV04 & $0.8 \mathrm{CDEFGH}$ & $2.9 \mathrm{AB}$ & $3.6 \mathrm{ABC}$ \\
\hline EB03 & $0.8 \mathrm{CDEFGH}$ & $1.8 \mathrm{ABC}$ & $2.5 \mathrm{BC}$ \\
\hline YV10 & $0.7 \mathrm{CDEFGH}$ & $2.7 \mathrm{AB}$ & $3.4 \mathrm{ABC}$ \\
\hline MN902 & 0.7 CDEFGH & $2.0 \mathrm{ABC}$ & $2.7 \mathrm{ABC}$ \\
\hline EB901 & 0.7 CDEFGH & $1.7 \mathrm{ABC}$ & $2.4 \mathrm{BC}$ \\
\hline VY10 & 0.7 CDEFGH & $1.9 \mathrm{ABC}$ & $2.6 \mathrm{BC}$ \\
\hline WN01 & 0.7 DEFGH & $2.8 \mathrm{AB}$ & $3.5 \mathrm{ABC}$ \\
\hline EB01 & 0.7 DEFGH & $2.4 \mathrm{ABC}$ & $3.1 \mathrm{ABC}$ \\
\hline $\mathrm{CH} 01$ & $0.7 \mathrm{DEFGH}$ & $1.9 \mathrm{ABC}$ & $2.6 \mathrm{BC}$ \\
\hline RB09 & 0.6 DEFGH & $1.7 \mathrm{ABC}$ & $2.4 \mathrm{BC}$ \\
\hline RB01 & $0.6 \mathrm{EFGH}$ & $2.3 \mathrm{ABC}$ & $2.9 \mathrm{ABC}$ \\
\hline YV36 & $0.6 \mathrm{EFGH}$ & $2.4 \mathrm{ABC}$ & $3.0 \mathrm{ABC}$ \\
\hline AL32 & $0.6 \mathrm{FGH}$ & $2.0 \mathrm{ABC}$ & $2.5 \mathrm{BC}$ \\
\hline YV150 & $0.5 \mathrm{GH}$ & $2.2 \mathrm{ABC}$ & $2.7 \mathrm{ABC}$ \\
\hline GC02 & $0.4 \mathrm{GH}$ & $2.6 \mathrm{AB}$ & $3.1 \mathrm{ABC}$ \\
\hline DV06 & $0.4 \mathrm{H}$ & $2.3 \mathrm{ABC}$ & $2.8 \mathrm{ABC}$ \\
\hline
\end{tabular}

y VCG co-inoculated with CG136. Isolates used from each VCG are listed in Table 1.

z Numbers of VCG CG136 and co-infecting VCG conidia were calculated by multiplying the total number of conidia by the percentage of each VCG as determined by pyrosequencing. Data were log transformed prior to mixed model analysis of the combined trials. The total number of conidia $(P=0.0002)$ and numbers of conidia produced by CG136 $(P<0.0001)$ and the co-infecting VCG $(P=0.0003)$ were significantly different among co-inoculation treatments. Means followed by the same letter are not significantly different with Tukey-Kramer groupings for least-square means. amounts of standard and challenge VCGs. If the co-inoculated VCGs were equally competitive, the standard VCG would comprise $50 \%$ of $A$. flavus DNA at termination. However, observed proportions of the standard VCG were 15.4 to $54.3 \%$, reflecting a wide range of competitive ability among the challenge VCGs. The co-infection experiment was performed twice, and differences among isolates in both proportion of total A. flavus DNA and ranking for competitive ability were reproducible, indicating that competitive ability is a characteristic of specific isolates. However, though each isolate belonged to a distinct VCG, we do not know if the observed competitiveness is a characteristic of the VCG or just the examined isolate. Recently, microsatellite markers were developed that reveal considerable variability within VCGs of A. flavus (28). The gradient of competitive ability observed in this study suggests that multiple genes influence competitive ability. Further work will be required to determine whether competitive ability during host infection is more consistent within than between VCGs.

Intraspecific competition within A. flavus has been examined $(15,61,62)$ but this is the first study to quantify variation in competitive ability among many isolates. Diverse assemblages of A. flavus exist both in soil and on crops $(4,31,49)$, and interactions among VCGs occur throughout the environment. Less-competitive VCGs would be expected to become rare or absent from the environment over time but divergent adaptations to different ecological niches or life strategies facilitate the coexistence of closely related microorganisms $(36,41,42)$. VCGs varied in both invasion of host tissues and sporulation during co-infection but the observation that the best colonizers were not the best sporulators indicates VCGs have different life strategies. Differences in strategy among VCGs might be explained by considering VCGs to express different proportions of two general strategies: strategy 1 , colonize-disperse, and strategy 2, ramify-hold. Several isolates may coexist on a single ear of maize, with some succeeding by superficial infection followed by rapid sporulation (strategy 1: colonize-disperse) and others by deeply invading host tissues (strategy 2: ramify-hold).

Our results suggest that aflatoxin-producing ability has differential importance for the two strategies. During co-infection, atoxigenic isolates were better sporulators, on average, than toxigenic isolates. The top six sporulators were atoxigenic, suggesting that some atoxigenics favor colonize-disperse strategies. Although there was no correlation between toxigenicity and competitive ability during kernel invasion, aflatoxin-producing ability may favor ramify-hold strategies by providing selective advantage in retaining plant substrates by reducing herbivory (6). Fitness costs associated with resistance to herbivory have been observed in plants (59), and resources required for aflatoxin production may have a similar fitness cost reflected in reduced sporulation (51). This is in contrast to studies that found a positive relationship between toxin production and sporulation in A. nidulans (63), A. parasiticus, and A. flavus (60). However, isolates were grown in axenic culture and not subject to the effects of competition; when nutrients are limiting, the cost of producing aflatoxin may reduce the reproductive capacity of the fungus. The S-strain may be an extreme example of the ramify-hold strategy because isolates typically produce few conidia and high concentrations of aflatoxin (10).

The colonize-disperse strategy is epidemiologically important because even small differences in sporulation may have large influences on the composition of crop-associated A. flavus communities. For example, if isolate $\mathrm{X}$ has a three to two advantage over isolate $\mathrm{Y}, \mathrm{X}$ will comprise $60 \%$ of the spores after one generation and more than $90 \%$ after six generations. Thus, isolates that contribute the greatest proportion of conidia during competition for host resources dominate A. flavus communities associated with crop production and have a proportional influence on contamination regardless of how competitive isolates are 
during ramification of host tissues. This may be an important aspect of the success of atoxigenic strains in biocontrol of aflatoxin contamination (19).

In addition to infecting many plant species (21), A. flavus is the second most common causal agent of Aspergillus infections in humans (29), and frequently infects insects (55). St. Leger et al. (57) concluded that A. flavus lacks host specialization because, even though individual isolates vary in virulence, human-, insect-, and plant-derived isolates all cause disease in both the animal and plant kingdoms. However, Scully and Bidochka $(55,56)$ found host restriction after serial passage of $A$. flavus through an insect. Larval mortality did not increase but the number of conidia produced on the larvae did, and growth and sporulation on plant hosts declined. Increased sporulation during competition on a host may be an early adaptive step in the path to host specificity; increased reproduction on a host confers a more frequent association that may be important in evolution of host specificity from a generalist life strategy.

Differences in competitiveness of A. flavus isolates should be considered when selecting for resistant crops. Maize lines resistant to aflatoxin contamination are known (8) but host-specific interactions between crops and different $A$. flavus isolates have not been taken into account. Variation among VCGs in ability to overcome host defenses may have contributed to the observed differences in competitive ability. Isolates used in this study originated from soil and cottonseed from regions where both cotton and maize are grown (35); therefore, even though the isolates were not from maize, the VCGs exist in maize-cotton rotations. VCG frequencies on maize are unknown but it would be interesting to test the extent to which the most competitive VCGs in the current study are the most common on maize. Breeding for resistance should include the isolates most competitive and common on the target crop in order to optimize selection. Similarly, efficacy of biocontrol may be influenced by host specificity
(37), and competitive ability on a specific crop should be evaluated when selecting biocontrol strains.

Individual crop components are frequently infected with mixtures of A. flavus VCGs (4) and the resulting intraspecific interactions influence the extent to which crops become contaminated with aflatoxins. Effects of intraspecific competition on

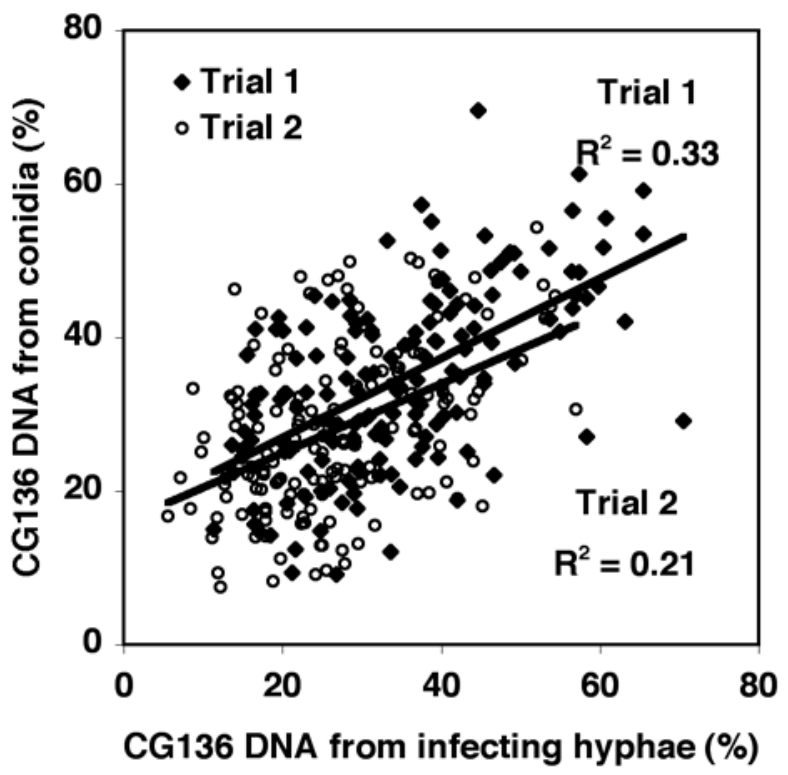

Fig. 2. Relationship between proportions of vegetative compatibility group (VCG) CG136 DNA from maize kernels and conidia from the surface of maize kernels. Kernels were co-infected with CG136 and 1 of 38 other VCGs. Proportions were quantified by pyrosequencing. For each trial, four replicates per co-inoculated VCG pair are shown.

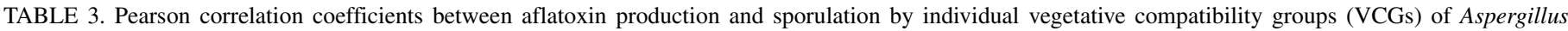

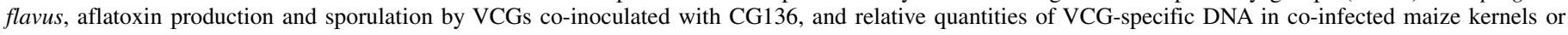
conidia produced on co-infected maize kernels s

\begin{tabular}{|c|c|c|c|c|c|c|c|c|c|}
\hline Variables & $\begin{array}{c}\text { Kernel } \\
\text { aflatoxin } \\
(\text { single } \\
\text { VCG)t }\end{array}$ & $\begin{array}{c}\text { Kernel } \\
\text { aflatoxin } \\
(\text { co- } \\
\text { infection })^{\mathrm{u}}\end{array}$ & $\begin{array}{c}\text { Kernel DNA } \\
(\%)^{\mathrm{v}}\end{array}$ & $\begin{array}{c}\text { Conidia } \\
\text { aflatoxin } \\
(\text { single } \\
\text { VCG })^{\mathrm{w}}\end{array}$ & $\begin{array}{l}\text { Conidia } \\
\text { aflatoxin } \\
(\text { co- } \\
\text { infection) }\end{array}$ & $\begin{array}{c}\text { Conidia } \\
\text { DNA } \\
(\%)^{\mathrm{x}}\end{array}$ & $\begin{array}{c}\text { Conidia of } \\
\text { CG136y }\end{array}$ & $\begin{array}{c}\text { Conidia of } \\
\text { non-CG136 } \\
\mathrm{VCG}^{\mathrm{z}}\end{array}$ & $\begin{array}{c}\text { Total conidia } \\
\text { (co- } \\
\text { infection) }\end{array}$ \\
\hline \multirow[t]{2}{*}{ Kernel aflatoxin (co-infection) } & 0.89 & .. & $\cdots$ & $\cdots$ & $\ldots$ & $\cdots$ & $\cdots$ & $\ldots$ & $\ldots$ \\
\hline & $<0.0001$ & $\ldots$ & $\ldots$ & $\ldots$ & $\ldots$ & $\ldots$ & $\ldots$ & $\ldots$ & $\ldots$ \\
\hline \multirow[t]{2}{*}{ Kernel DNA (\%) } & -0.21 & -0.27 & $\ldots$ & $\ldots$ & $\ldots$ & $\ldots$ & $\ldots$ & $\ldots$ & $\ldots$ \\
\hline & 0.19 & 0.1 & $\ldots$ & $\ldots$ & $\ldots$ & $\ldots$ & $\ldots$ & $\ldots$ & $\ldots$ \\
\hline \multirow[t]{2}{*}{ Conidia aflatoxin (single VCG) } & 0.93 & 0.88 & -0.18 & $\ldots$ & $\ldots$ & $\ldots$ & $\ldots$ & $\ldots$ & $\ldots$ \\
\hline & $<0.0001$ & $<0.0001$ & 0.29 & $\ldots$ & $\ldots$ & $\ldots$ & $\ldots$ & $\ldots$ & $\ldots$ \\
\hline \multirow[t]{2}{*}{ Conidia aflatoxin (co-infection) } & 0.92 & 0.93 & -0.23 & 0.88 & $\ldots$ & $\ldots$ & $\ldots$ & $\ldots$ & $\ldots$ \\
\hline & $<0.0001$ & $<0.0001$ & 0.16 & $<0.0001$ & $\ldots$ & $\ldots$ & $\ldots$ & $\ldots$ & $\ldots$ \\
\hline \multirow[t]{2}{*}{ Conidia DNA (\%) } & -0.4 & -0.55 & 0.6 & -0.45 & -0.4 & $\ldots$ & $\ldots$ & $\ldots$ & $\ldots$ \\
\hline & 0.01 & 0.0003 & $<0.0001$ & 0.005 & 0.01 & $\ldots$ & $\ldots$ & $\ldots$ & $\ldots$ \\
\hline \multirow{2}{*}{ Conidia of CG136 } & 0.34 & 0.56 & -0.46 & 0.38 & 0.35 & -0.87 & $\ldots$ & $\ldots$ & $\ldots$ \\
\hline & 0.03 & 0.0002 & 0.004 & 0.02 & 0.03 & $<0.0001$ & $\ldots$ & $\ldots$ & $\ldots$ \\
\hline \multirow{2}{*}{ Conidia of non-CG136 VCG } & -0.35 & -0.25 & 0.46 & -0.35 & -0.28 & 0.6 & -0.19 & $\ldots$ & $\ldots$ \\
\hline & 0.03 & 0.12 & 0.004 & 0.03 & 0.09 & $<0.0001$ & 0.25 & $\ldots$ & $\ldots$ \\
\hline \multirow[t]{2}{*}{ Total conidia (co-infection) } & -0.08 & 0.15 & 0.11 & -0.06 & -0.02 & -0.04 & 0.49 & 0.76 & $\ldots$ \\
\hline & 0.62 & 0.38 & 0.52 & 0.71 & 0.91 & 0.83 & 0.002 & $<0.0001$ & $\ldots$ \\
\hline \multirow[t]{2}{*}{ Total conidia (single VCG) } & -0.04 & 0.003 & 0.08 & -0.05 & -0.06 & 0.23 & -0.03 & 0.51 & 0.43 \\
\hline & 0.83 & 0.99 & 0.64 & 0.76 & 0.73 & 0.16 & 0.84 & 0.001 & 0.008 \\
\hline
\end{tabular}

s Top values are Pearson product moment correlations $(r)$; bottom values are $P$ values.

${ }^{t}$ Aflatoxin $B_{1}(\mathrm{ppb})$ in infected kernels inoculated with individual VCGs.

u Aflatoxin $\mathrm{B}_{1}(\mathrm{ppb})$ in infected kernels co-inoculated with each of 38 VCGs and VCG CG136.

${ }^{v}$ Kernel DNA is the percentage of A. flavus DNA from co-infected kernels contributed by the non-CG136 VCG. This is a measure of VCG competitiveness.

${ }^{w}$ Aflatoxin $B_{1}(\mathrm{ppb})$ in conidia produced on kernels inoculated with individual VCGs.

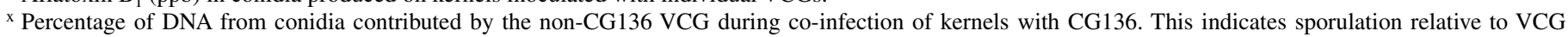
CG136.

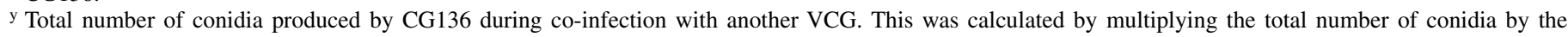
percentage conidial DNA from CG136.

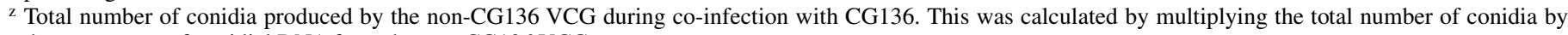
the percentage of conidial DNA from the non-CG136 VCG. 
aflatoxin production were quantified in this and previous studies $(11,15,16,24,27,32,61,62)$. The high resolution allowed by the pyrosequencing assay used in this study permitted identification of both isolates for which competitive exclusion is sufficient to explain aflatoxin reductions and isolates that reduce aflatoxin significantly more than predicted by competitive exclusion. This is similar to previously published observations where some atoxigenics apparently function by competitive exclusion alone (32) and others reduce contamination through a combination of competitive exclusion and a second, undefined mechanism that presumably disrupts aflatoxin biosynthesis independent of competition $(15,24,61)$. Although competitive exclusion is an important and dominant mechanism of biocontrol by atoxigenic isolates, influences on the regulation of aflatoxin biosynthesis through an unknown mechanism may be important to optimal reductions in aflatoxin contamination (15). Similarly, two VCGs that alone produced higher concentrations of aflatoxin than CG136 reduced aflatoxin when co-inoculated with CG136. Competitive interactions may reduce aflatoxin contamination even when A. flavus communities are composed of high aflatoxin producers; therefore, complexity of the fungal community may be important in modulating the aflatoxin content of plant tissues.

In the current study, aflatoxin concentrations in maize kernels and in conidia produced on kernel surfaces were correlated in both the single isolate and co-infection experiments. Thus, as crop aflatoxin content increases, so does the aflatoxin content of associated conidia. Airborne mycotoxins have significant health implications (26), and A. flavus is an important component of the airborne microflora in many environments $(7,43)$. Weekly averages of A. flavus at over $400 \mathrm{CFU} \mathrm{m}^{-3}$ have been quantified in air from agricultural areas (7). At this level, conidia of the most toxigenic isolate reported in the current study would result in daily exposure to $56 \mathrm{pg}$ of aflatoxin $\mathrm{B}_{1}$, assuming a standard breathing rate of $1 \mathrm{~m}^{3} \mathrm{~h}^{-1}$. Use of strains for biocontrol results in high proportions of atoxigenic conidia without increasing the total quantity of $A$. flavus in the air (7). This reduces exposure of humans and animals to aflatoxin via respiratory routes and, in so doing, may provide an additional health benefit of atoxigenic strain use (19).

Previous measurements of competition during host infection have either relied on isolations of $A$. flavus and complementation of nitrate nonutilizing auxotrophs (nit mutants) to identify VCGs $(12,15)$ or used aflatoxin concentrations as a measure of

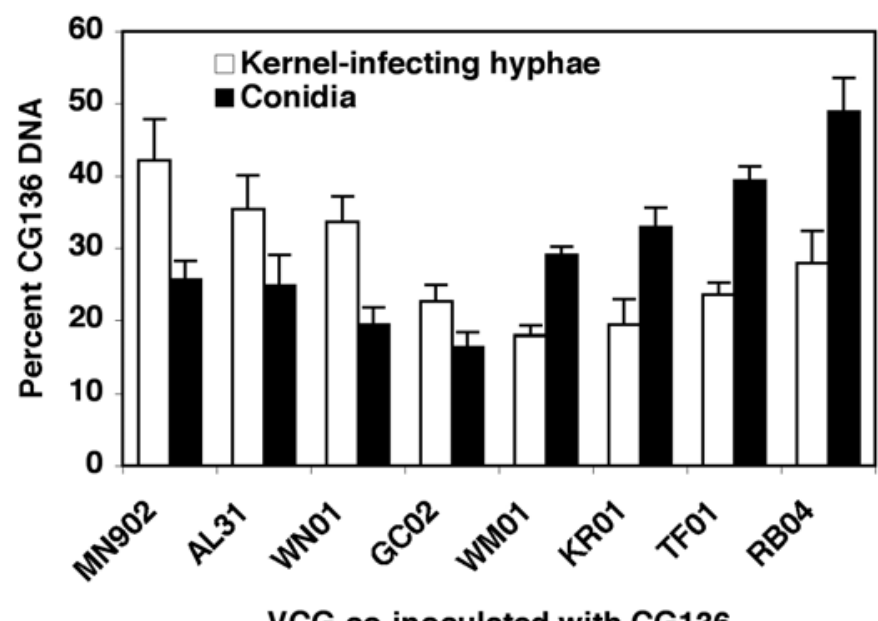

Fig. 3. Vegetative compatibility groups (VCGs) of Aspergillus flavus for which the proportion of VCG CG136 DNA in infecting hyphae differs significantly from the proportion in conidia from co-inoculated maize kernels. Percent CG136 DNA is the proportion of total A. flavus DNA composed of CG136 and is inversely proportional to the percent of non-CG136 DNA. Error bars indicate one standard error. competition between atoxigenic and toxigenic isolates $(11,16$, 27,61). In this study, pyrosequencing was used to quantify the proportion of CG136 from mixtures of A. flavus DNA with a high level of resolution and reproducibility ( $\mathrm{SD} \leq 1 \%$ ). Sampling error is greatly reduced here compared with estimates of VCG frequency by complementation of nit mutants $(4,15,31)$, where there is a low likelihood of identifying rare VCGs. With pyrosequencing, a VCG that is $1 \%$ of the total A. flavus in a sample can be detected. Real-time PCR can distinguish and quantify closely related microorganisms but is limited by the requirement for multiple primers or probes and the inaccuracy of quantification at the lower limits of detection $(3,39,45)$. With realtime quantitative PCR, variability increases as DNA concentrations decrease, and the limits of quantification can be as much as 100 times higher than the limits of detection (45). For example, when competition between isolates of Pochonia chlamydosporia colonizing tomato roots was examined, fungal DNA was below limits of quantification in some replicates, so percentages of the target isolate were highly variable (coefficient of variation $\approx 100 \%$ ) and significant differences among treatments could not be determined (3). With pyrosequencing, SNPs can be used to quantify frequencies of multiple isolates simultaneously, and even small quantities of DNA can be analyzed using nested PCR (20). Sensitivity and precision make pyrosequencing a useful tool for studying interactions in the environment among microorganisms for which sequence data is available.

TABLE 4. Concentrations and total quantities of aflatoxin $\mathrm{B}_{1}$ produced by individual isolates of Aspergillus flavus from different vegetative compatibility groups (VCGs) on living maize kernels ${ }^{\mathrm{v}}$

\begin{tabular}{|c|c|c|c|c|}
\hline $\mathrm{VCG}^{\mathrm{w}}$ & $\begin{array}{c}\text { Kernel } \\
\text { aflatoxin } \\
(\mu \mathrm{g} / \mathrm{g})^{\mathrm{x}}\end{array}$ & $\begin{array}{l}\text { Conidia } \\
\text { aflatoxin } \\
(\mu \mathrm{g} / \mathrm{g})^{\mathrm{y}}\end{array}$ & $\begin{array}{c}\text { Total kernel } \\
\text { aflatoxin }(\mu \mathrm{g})^{\mathrm{z}}\end{array}$ & $\begin{array}{c}\text { Total conidia } \\
\text { aflatoxin } \\
(\mu \mathrm{g})\end{array}$ \\
\hline YV13 & $194 \mathrm{~A}$ & $35 \mathrm{~A}$ & $775 \mathrm{~A}$ & $4.0 \mathrm{~A}$ \\
\hline VY10 & $174 \mathrm{AB}$ & $26 \mathrm{AB}$ & $692 \mathrm{AB}$ & $2.7 \mathrm{AB}$ \\
\hline BR02 & $150 \mathrm{ABC}$ & $20 \mathrm{AB}$ & $607 \mathrm{ABC}$ & $2.1 \mathrm{ABC}$ \\
\hline CG136 & $141 \mathrm{ABC}$ & $23 \mathrm{AB}$ & $550 \mathrm{ABCD}$ & $2.2 \mathrm{ABC}$ \\
\hline DV901 & $138 \mathrm{ABC}$ & $42 \mathrm{~A}$ & $569 \mathrm{ABC}$ & $2.9 \mathrm{AB}$ \\
\hline $\mathrm{CH} 01$ & $121 \mathrm{ABCD}$ & $24 \mathrm{AB}$ & $476 \mathrm{ABCDE}$ & $2.1 \mathrm{ABC}$ \\
\hline OD02 & $109 \mathrm{ABCDE}$ & $29 \mathrm{AB}$ & $429 \mathrm{ABCDE}$ & $3.4 \mathrm{ABC}$ \\
\hline EB901 & $105 \mathrm{ABCDE}$ & $17 \mathrm{AB}$ & $428 \mathrm{ABCDE}$ & $1.1 \mathrm{ABC}$ \\
\hline TF01 & 92 BCDEF & $25 \mathrm{AB}$ & $371 \mathrm{BCDEF}$ & $2.7 \mathrm{ABC}$ \\
\hline KR01 & $90 \mathrm{CDEFG}$ & $27 \mathrm{AB}$ & $358 \mathrm{CDEF}$ & $3.3 \mathrm{ABC}$ \\
\hline RB07 & 69 DEFGH & $11 \mathrm{AB}$ & $277 \mathrm{DEFG}$ & $1.0 \mathrm{ABC}$ \\
\hline RB04 & 64 DEFGHI & $21 \mathrm{AB}$ & $255 \mathrm{EFG}$ & $2.3 \mathrm{ABC}$ \\
\hline WM01 & 59 EFGHIJ & $13 \mathrm{AB}$ & $239 \mathrm{EFGH}$ & $1.3 \mathrm{ABC}$ \\
\hline WN03 & 52 FGHIJ & $10 \mathrm{AB}$ & 208 FGH & $1.1 \mathrm{ABC}$ \\
\hline RB01 & 48 GHIJK & $5 \mathrm{AB}$ & 196 FGHI & $0.6 \mathrm{ABC}$ \\
\hline EC01 & 47 HIJKL & $17 \mathrm{AB}$ & 190 FGHIJ & $2.0 \mathrm{ABC}$ \\
\hline RB09 & 37 HIJKLM & $9 \mathrm{AB}$ & 154 GHIJK & $0.4 \mathrm{BC}$ \\
\hline EB01 & 35 HIJKLM & $10 \mathrm{AB}$ & 146 GHIJK & $0.8 \mathrm{ABC}$ \\
\hline MR17 & 33 JKLM & $4 \mathrm{AB}$ & 134 HIJK & $0.4 \mathrm{BC}$ \\
\hline YV10 & 32 IJKLM & $6 \mathrm{AB}$ & 135 GHIJK & $0.6 \mathrm{ABC}$ \\
\hline BR01 & $25 \mathrm{KLM}$ & $8 \mathrm{AB}$ & 103 IJK & $0.8 \mathrm{ABC}$ \\
\hline MN902 & $24 \mathrm{LM}$ & $5 \mathrm{~B}$ & $94 \mathrm{JK}$ & $0.3 \mathrm{C}$ \\
\hline DE01 & $21 \mathrm{M}$ & $5 \mathrm{~B}$ & $87 \mathrm{~K}$ & $0.4 \mathrm{BC}$ \\
\hline OD01 & $0.30 \mathrm{~N}$ & $0.01 \mathrm{C}$ & $1.3 \mathrm{~L}$ & $0.002 \mathrm{D}$ \\
\hline ST02 & $0.22 \mathrm{~N}$ & ND & $0.88 \mathrm{~L}$ & ND \\
\hline EB03 & $0.15 \mathrm{~N}$ & ND & $0.59 \mathrm{~L}$ & ND \\
\hline
\end{tabular}

${ }^{v} \mathrm{ND}$, none detected. The limit of detection for aflatoxin $\mathrm{B}_{1}$ in the conidia was $0.2 \mu \mathrm{g} / \mathrm{g}$.

${ }^{w}$ Isolates from each of the VCGs are listed in Table 1.

${ }^{x}$ Kernel aflatoxin is the mean concentration of aflatoxin $\mathrm{B}_{1}$ extracted from maize kernels after conidia were washed from the surface. All aflatoxin data were $\log$ transformed prior to analysis of the combined trials. Kernel and conidia aflatoxin were significantly different among isolates (VCGs) $(P<0.0001)$. Means followed by the same letter are not significantly different with Tukey-Kramer grouping for least-square means.

y Conidia aflatoxin is the mean concentration of aflatoxin $\mathrm{B}_{1}$ extracted from conidia washed from the surface of the maize kernels.

$\mathrm{z}$ Total kernel and conidia aflatoxin were calculated by multiplying the concentration of aflatoxin $\mathrm{B}_{1}$ by the total dry weight of the kernels or conidia. 
The atoxigenic biocontrol strain AF36 (isolate YV36 in this study), which has been applied commercially to cotton (14), ranked fifth for competitiveness among the atoxigenic isolates but second for aflatoxin reduction in kernels. AF36 reduced aflatoxin significantly more than predicted by competitive exclusion alone. Overall, AF36 ranked 13 among 38 isolates for competitiveness and was more competitive than the highest aflatoxin producers in this study. For reduction of sporulation by the co-infecting isolate, AF36 ranked fifth and displaced CG136 conidia by $78 \%$. Superior competitive ability during tissue invasion and reproduction com- bined with excellent interference with aflatoxin biosynthesis help to explain the efficacy of AF36 in reducing aflatoxin contamination (14). Identification of isolates with competitive abilities similar or superior to those of AF36 suggests that many highly effective atoxigenic strains may be available for use as biocontrol agents. Several of the isolates examined in the current work may have such value.

The pyrosequencing assays described in the current study may provide insights for selection of additional atoxigenic strains for biocontrol. Atoxigenic VCGs vary in ability to reduce crop

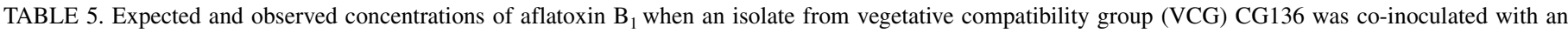
isolate from a different VCG

\begin{tabular}{|c|c|c|c|c|}
\hline \multirow[b]{3}{*}{$\mathrm{VCG}^{\mathrm{y}}$} & \multicolumn{4}{|c|}{ Aflatoxin $\mathrm{B}_{1}$ relative to aflatoxin produced by VCG CG136 alone ${ }^{\mathrm{z}}$} \\
\hline & \multicolumn{2}{|c|}{ Infected maize kernels } & \multicolumn{2}{|c|}{ Conidia from surface of kernels } \\
\hline & Expected (SE) & Observed (SE) & Expected (SE) & Observed (SE) \\
\hline YV13 & $128(9)$ & $107(11)$ & $141(15)$ & $101(22)$ \\
\hline VY10 & $129(18)$ & $89(10)$ & $142(33)$ & $104(27)$ \\
\hline BR02 & $110(9)$ & $69(7)^{*}$ & $95(7)$ & $94(25)$ \\
\hline CG136 & 100 & 100 & 100 & 100 \\
\hline DV901 & $104(7)$ & $83(11)$ & $171(50)$ & $93(14)$ \\
\hline $\mathrm{CH} 01$ & $96(7)$ & $79(16)$ & $129(30)$ & $87(11)$ \\
\hline OD02 & $87(6)$ & $63(11)$ & $111(16)$ & $64(8)^{*}$ \\
\hline EB901 & $86(5)$ & $72(9)$ & $101(27)$ & $105(26)$ \\
\hline KR01 & $74(8)$ & $75(8)$ & $119(21)$ & $88(14)$ \\
\hline TF01 & $79(7)$ & $88(8)$ & 109(12) & $61(8)^{*}$ \\
\hline RB07 & $70(5)$ & $43(5)^{*}$ & $72(7)$ & 49 (14) \\
\hline RB04 & $65(5)$ & $57(8)$ & $106(12)$ & $33(4) * *$ \\
\hline WM01 & $57(6)$ & $60(9)$ & 77 (9) & $49(10)$ \\
\hline WN03 & $60(4)$ & 67 (10) & $64(5)$ & 65 (17) \\
\hline EC01 & $58(2)$ & 72 (11) & $86(4)$ & $88(23)$ \\
\hline RB01 & $55(5)$ & $36(5) *$ & $48(6)$ & $30(8)$ \\
\hline RB09 & $52(5)$ & $25(4)^{* * *}$ & $56(10)$ & $33(8)$ \\
\hline EB01 & $40(4)$ & $26(3)^{*}$ & $58(10)$ & $38(14)$ \\
\hline MR17 & $66(2)$ & $45(5)^{*}$ & $58(3)$ & 48 (11) \\
\hline YV10 & 37 (3) & $30(3)$ & $48(6)$ & $25(4)^{*}$ \\
\hline BR01 & $53(1)$ & $44(9)$ & $67(5)$ & $37(10)^{*}$ \\
\hline MN902 & $53(2)$ & $36(6)^{*}$ & $44(8)$ & $28(5)$ \\
\hline DE01 & $42(3)$ & 47 (10) & $41(6)$ & 39 (14) \\
\hline OD01 & $26(0.09)$ & 40 (12) & $36(0.07)$ & $20(6)^{*}$ \\
\hline ST02 & $32(0.04)$ & $37(8)$ & $31(0)$ & $21(5)$ \\
\hline EB03 & $28(0.02)$ & $15(3)^{*}$ & $30(0)$ & $13(3)^{* * *}$ \\
\hline
\end{tabular}

y VCGs are ordered from highest to lowest aflatoxin producers on maize kernels inoculated with a single VCG.

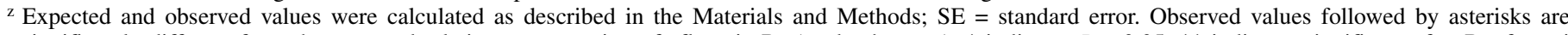
significantly different from the expected relative concentration of aflatoxin $\mathrm{B}_{1}$ (student's $t$ test); * indicates $P<0.05$; ** indicates significant after Bonferroni adjustment for multiple comparisons, $P<0.002$.

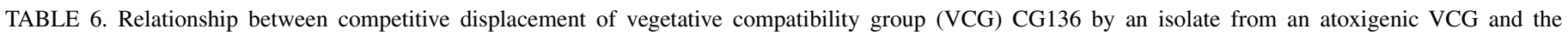
reduction of aflatoxin $\mathrm{B}_{1}$ in infected maize kernels and conidia washed from the surface of the kernels ${ }^{\mathrm{x}}$

\begin{tabular}{|c|c|c|c|c|c|c|}
\hline \multirow[b]{2}{*}{ VCG } & \multicolumn{3}{|c|}{ Kernels $^{\mathrm{y}}$} & \multicolumn{3}{|c|}{ Conidia $^{z}$} \\
\hline & Reduction (SE) & Displacement (SE) & $P$ & Reduction (SE) & Displacement (SE) & $P$ \\
\hline DV06 & 88 (4) A & $78(3) \mathrm{AB}$ & 0.006 & $80(9) \mathrm{A}$ & $83(2) \mathrm{AB}$ & 0.78 \\
\hline YV36 & 86 (4) $\mathrm{AB}$ & $74(2) \mathrm{AB}$ & 0.01 & $82(7) \mathrm{A}$ & 78 (3) ABCD & 0.38 \\
\hline YV150 & $86(4) \mathrm{AB}$ & $73(2) \mathrm{AB}$ & 0.003 & $90(2) \mathrm{A}$ & 82 (2) ABC & 0.07 \\
\hline GC02 & $83(5) \mathrm{AB}$ & 77 (2) $A B$ & 0.24 & 88 (4) A & 84 (2) A & 0.21 \\
\hline WN01 & $83(4) \mathrm{AB}$ & $66(4) \mathrm{AB}$ & 0.009 & $86(6) \mathrm{A}$ & 81 (2) ABCD & 0.27 \\
\hline MR34 & 80 (3) ABC & 61 (3) B & 0.0009 & $80(5) \mathrm{A}$ & $62(3) \mathrm{CDE}$ & 0.0009 \\
\hline AL32 & 79 (6) ABC & $68(5) \mathrm{AB}$ & 0.001 & $78(6) \mathrm{A}$ & 78 (2) ABCD & 0.90 \\
\hline TI01 & 79 (5) ABC & 81 (4) A & 0.47 & 85 (4) A & 67 (4) ABCDE & 0.0002 \\
\hline YV04 & 74 (4) ABC & 82 (1) A & 0.11 & $79(5) \mathrm{A}$ & 79 (2) ABCD & 0.92 \\
\hline RB02 & 67 (6) BCD & 62 (2) B & 0.45 & $74(8) \mathrm{A}$ & $62(2) \mathrm{DE}$ & 0.19 \\
\hline AL31 & $60(7) \mathrm{CD}$ & $65(5) \mathrm{AB}$ & 0.34 & $71(12) \mathrm{A}$ & 75 (4) ABCDE & 0.68 \\
\hline MR30 & $60(6) \mathrm{CD}$ & $61(5) \mathrm{B}$ & 0.86 & 74 (4) A & 57 (4) E & 0.01 \\
\hline WS23 & $57(8) \mathrm{C}$ & 68 (2) AB & 0.26 & 67 (10) A & 64 (2) BCDE & 0.81 \\
\hline
\end{tabular}

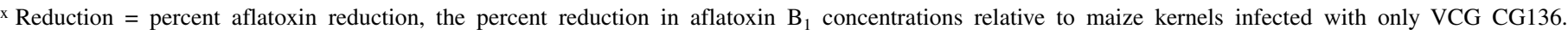
Percentage data were arcsine transformed prior to mixed model analysis of the combined trials. Means followed by the same letter are not significantly different with Tukey-Kramer groupings for least-square means. Displacement = percent displacement of VCG CG136, the percentage of Aspergillus flavus DNA from coinfected maize kernels contributed by the atoxigenic VCG. SE = standard error. Percent aflatoxin reduction and percent displacement were compared with a paired $t$ test. Significant $P$ values after Bonferroni adjustment for multiple comparisons is $P<0.004$.

y Kernels indicates co-infected maize kernels.

${ }^{\mathrm{z}}$ Conidia were washed from the surface of the co-infected maize kernels. 
aflatoxin content when co-inoculated with aflatoxin producers $(2,11,16)$, and this is one criterion for selection of atoxigenics for biocontrol. In the current study, ability to reduce aflatoxins, competitive ability, and sporulation during competition were measured for each atoxigenic VCG; the most competitive isolates were not necessarily either the most effective at reducing aflatoxin contamination or the best sporulators. For example, VCG TI01 was the second most competitive of the 13 atoxigenic isolates but ranked 8 and 9 for aflatoxin reduction and sporulation, respectively. VCG DV06 was slightly less competitive than VCG TI01 but reduced toxin by $88 \%$ compared with $79 \%$ and comprised $83 \%$ compared with $67 \%$ of the conidia from coinfected maize kernels. Based on this study, DV06 has the potential to be a slightly more effective biocontrol strain than AF36. The best isolate for long-term biocontrol is one that both reduces aflatoxin on the treated crop and remains a dominant component of the A. flavus community over multiple years (19). Understanding interactions between genetically diverse atoxigenic and toxigenic isolates will aid in the design of biocontrol strategies to induce long-term, relatively stable reductions in the average aflatoxin-producing potential of fungal communities.

\section{ACKNOWLEDGMENTS}

We thank the members of the Cotty lab, especially D. Downey and J. Tran, for laboratory assistance with this work. This work was supported by the United States Department of Agriculture-Agricultural Research Service CRIS project 5347-42000-019-00D.

\section{LITERATURE CITED}

1. Atehnkeng, J., Ojiambo, P. S., Donner, M., Ikotun, T., Sikor, R. A., Cotty, P. J., and Bandyopadhyay, R. 2008. Distribution and toxigenicity of Aspergillus species isolated from maize kernels from three agroecological zones in Nigeria. Int. J. Food Microbiol. 122:74-84.

2. Atehnkeng, J., Ojiambo, P. S., Ikotun, T., Sikora, R. A., Cotty, P. J., and Bandyopadhyay, R. 2008. Evaluation of atoxigenic isolates of Aspergillus flavus as potential biocontrol agents for aflatoxin in maize. Food Addit. Contam. 25:1266-1273.

3. Atkins, S. D., Peteira, B., Clark, I. M., Kerry, B. R., and Hirsch, P. R. 2009. Use of real-time quantitative PCR to investigate root and gall colonisation by co-inoculated isolates of the nematophagous fungus Pochonia chlamydosporia. Ann. Appl. Biol. 155:143-152.

4. Bayman, P., and Cotty, P. J. 1991. Vegetative compatibility and genetic diversity in the Aspergillus flavus population of a single field. Can. J. Bot. 69:1707-1711.

5. Bayman, P., and Cotty, P. J. 1993. Genetic diversity in Aspergillus flavus: association with aflatoxin production and morphology. Can. J. Bot. 71:2334.

6. Bilgrami, K. S., and Sinha, K. K. 1992. Aflatoxins: their biological effects and ecological significance. Pages 59-86 in: Handbook of Applied Mycology, Vol. 5, Mycotoxins in Ecological Systems. Marcel Dekker, Basel.

7. Bock, C. H., Mackey, B., and Cotty, P. J. 2004. Population dynamics of Aspergillus flavus in the air of an intensively cultivated region of southwest Arizona. Plant Pathol. 53:422-433.

8. Brown, R. L., Chen, Z.-Y., Cleveland, T. E., and Russin, J. S. 1999. Advances in the development of host resistance in corn to aflatoxin contamination by Aspergillus flavus. Phytopathology 89:113-117.

9. Cleveland, T. E., and Cotty, P. J. 1991. Invasiveness of Aspergillus flavus in wounded cotton bolls is associated with production of a specific fungal polygalacturonase. Phytopathology 81:155-158.

10. Cotty, P. J. 1989. Virulence and cultural characteristics of two Aspergillus flavus strains pathogenic on cotton. Phytopathology 79:808-814.

11. Cotty, P. J. 1990. Effect of atoxigenic strains of Aspergillus flavus on aflatoxin contamination of developing cottonseed. Plant Dis. 74:233-235.

12. Cotty, P. J. 1994. Influence of field application of an atoxigenic strain of Aspergillus flavus on the populations of A. flavus infecting cotton bolls and on aflatoxin content of cottonseed. Phytopathology 84:1270-1277.

13. Cotty, P. J. 1997. Aflatoxin producing potential of communities of Aspergillus section Flavi from cotton producing areas in the United States. Mycol. Res. 101:698-704.

14. Cotty, P. J., Antilla, L., and Wakelyn, P. J. 2007. Competitive exclusion of aflatoxin producers: farmer driven research and development. Pages 241253 in: Biological Control: A Global Perspective. CABI, Oxfordshire, UK.
15. Cotty, P. J., and Bayman, P. 1993. Competitive exclusion of a toxigenic strain of Aspergillus flavus by an atoxigenic strain. Phytopathology 83:1283-1287.

16. Cotty, P. J., and Bhatnagar, D. 1994. Variability among atoxigenic Aspergillus flavus strains in ability to prevent aflatoxin contamination and production of aflatoxin biosynthetic pathway enzymes. Appl. Environ. Microbiol. 60:2248-2251.

17. Cotty, P. J., Cleveland, T. E., Brown, R. L., and Mellon, J. E. 1990. Variation in polygalacturonase production among Aspergillus flavus isolates. Appl. Environ. Microbiol. 56:3885-3887.

18. Cotty, P. J., and Jaime-Garcia, R. 2007. Influences of climate on aflatoxin producing fungi and aflatoxin contamination. Int. J. Food Microbiol. 119:109-115.

19. Cotty, P. J., Probst, C., and Jaime-Garcia, R. 2008. Etiology and management of aflatoxin contamination. Pages 287-299 in: Mycotoxins: Detection Methods, Management, Public Health, and Agricultural Trade. CABI, Oxfordshire, UK.

20. Das, M. K., Ehrlich, E. C., and Cotty, P. J. 2008. Use of pyrosequencing to quantify incidence of a specific Aspergillus flavus strain within complex fungal communities associated with commercial cotton crops. Phytopathology 98:282-288.

21. Diener, U. L., Cole, R. J., Sanders, T. H., Payne, G. A., Lee, L. S., and Klich, M. A. 1987. Epidemiology of aflatoxin formation by Aspergillus flavus. Annu. Rev. Phytopathol. 25:249-270.

22. Donner, M., Atehnkeng, J., Sikora, A. R., Bandyopadhyay, R., and Cotty, P. J. 2009. Distribution of Aspergillus section Flavi in soils of maize fields in three agroecological zones of Nigeria. Soil Biol. Biochem. 41:37-41.

23. Dorner, J. W., Cole, R. J., Connick, W. J. Daigle, D. J., McGuire, M. R., and Shasha, B. S. 2003. Evaluation of biological control formulations to reduce aflatoxin contamination in peanuts. Biol. Control 26:318-324.

24. Ehrlich, K. 1987. Effect on aflatoxin production of competition between wild-type and mutant strains of Aspergillus parasiticus. Mycopathologia 97:93-96.

25. Ehrlich, K. C., Montalbano, B. G., and Cotty, P. J. 2007. Analysis of single nucleotide polymorphisms in three genes shows evidence for genetic isolation of certain Aspergillus flavus vegetative compatibility groups. FEMS Microbiol. Lett. 268:231-236.

26. Fischer, G., and Dott, W. 2003. Relevance of airborne fungi and their secondary metabolites for environmental, occupational and indoor hygiene. Arch. Microbiol. 179:75-82.

27. Garber, R. K., and Cotty, P. J. 1997. Formation of sclerotia and aflatoxins in developing cotton bolls infected by the $\mathrm{S}$ strain of Aspergillus flavus and potential for biocontrol with an atoxigenic strain. Phytopathology 87:940-945.

28. Grubisha, L. C., and Cotty, P. J. 2009. Twenty-four microsatellite markers for the aflatoxin-producing fungus Aspergillus flavus. Mol. Ecol. Resour. 9:264-267.

29. Hedayati, M. T., Pasqualotto, A. C., Warn, P. A., Bowyer, P., and Denning, D. W. 2007. Aspergillus flavus: human pathogen, allergen and mycotoxin producer. Microbiology 153:1677-1692.

30. Horn, B. W., and Dorner, J. W. 1999. Regional differences in production of aflatoxin $\mathrm{B}_{1}$ and cyclopiazonic acid by soil isolates of Aspergillus flavus along a transect within the United States. Appl. Environ. Microbiol. 65:1444-1449.

31. Horn, B. W., and Greene, R. L. 1995. Vegetative compatibility within populations of Aspergillus flavus, A. parasiticus, and A. tamarii from a peanut field. Mycologia 87:324-332.

32. Horn, B. W., Greene, R. L., and Dorner, J. W. 2000. Inhibition of aflatoxin $\mathrm{B}_{1}$ production by Aspergillus parasiticus using nonaflatoxigenic strains: role of vegetative compatibility. Biol. Control 17:147-154.

33. Horn, B. W., Greene, R. L., Sobolev, V. S., Dorner, J. W., Powell, J. H., and Layton, R. C. 1996. Association of morphology and mycotoxin production with vegetative compatibility groups in Aspergillus flavus, A. parasiticus, and A. tamarii. Mycologia 88:574-587.

34. Jaime-Garcia, R., and Cotty, P. J. 2006. Spatial distribution of Aspergillus flavus and its toxigenic strains on commercial cottonseed from south Texas and its relationship to aflatoxin contamination. Plant Pathol. 55:358-366.

35. Jaime-Garcia, R., and Cotty, P. J. 2006. Spatial relationships of soil texture and crop rotation to Aspergillus flavus community structure in south Texas. Phytopathology 96:599-607.

36. Johnson, Z. I., Zinser, E. R., Coe, A., McNulty, N. P., Woodward, E. M. S., and Chisholm, S. W. 2006. Niche partitioning among Prochlorococcus ecotypes along ocean-scale environmental gradients. Science 311:17371740.

37. Kloepper, J. W. 1996. Host specificity in microbe-microbe interactions. BioScience 46:406-409.

38. Lee, L. S., Wall, J. H., Cotty, P. J., and Bayman, P. 1990. Integration of ELISA with conventional chromatographic procedures for quantification of aflatoxin in individual cotton bolls, seeds, and seed sections. J. Assoc. 
Off. Anal. Chem. 73:581-584.

39. Lehman, S. M., Kim, W.-S., Castle, A. J., and Svircev, A. M. 2008. Duplex real-time polymerase chain reaction reveals competition between Erwinia amylovora and E. pyrifoliae on pear blossoms. Phytopathology 98:673-679.

40. Leslie, J. F. 1993. Fungal vegetative compatibility. Annu. Rev. Phytopathol. 31:127-150.

41. MacLean, R. C., Dickson, A., and Bell, G. 2005. Resource competition and adaptive radiation in a microbial microcosm. Ecol. Lett. 8:38-46.

42. Miller, S. R., Williams, C., Strong, A. L., and Carvey, D. 2009. Ecological specialization in a spatially structured population of the thermophilic cyanobacterium Mastigocladus laminosus. Appl. Environ. Microbiol. 75:729-734.

43. Morrow, M. B., Meyer, G. H., and Prince, H. E. 1964. A summary of airborne mold surveys. Ann. Allergy 22:575-587.

44. Novas, M. V., and Cabral, D. 2002. Association of mycotoxin and sclerotia production with compatibility groups in Aspergillus flavus from peanut in Argentina. Plant Dis. 86:215-219.

45. Okubara, P. A., Schroeder, K. L., and Paulitz, T. C. 2008. Identification and quantification of Rhizoctonia solani and $R$. oryzae using real-time polymerase chain reaction. Phytopathology 98:837-847.

46. Orum, T. V., Bigelow, D. M., Nelson, M. R., Howell, D. R., and Cotty, P. J. 1997. Spatial and temporal patterns of Aspergillus flavus strain composition and propagule density in Yuma County, AZ, soils. Plant Dis. 81:911-916.

47. Papa, K. E. 1986. Heterokaryon incompatibility in Aspergillus flavus. Mycologia 78:98-101.

48. Park, D. L, and Liang, B. 1993. Perspectives on aflatoxin control for human food and animal feed. Trends Food Sci. Technol. 4:334-342.

49. Pildain, M. B., Vaamonde, G., and Cabral, D. 2004. Analysis of population structure of Aspergillus flavus from peanut based on vegetative compatibility, geographic origin, mycotoxin and sclerotia production. Int. J. Food Microbiol. 93:31-40.

50. Pons, W. A., Robertson, J. A., and Goldblatt, L. A. 1966. Objective fluorometric measurement of aflatoxins on TLC plates. J. Am. Oil Chem. Soc. 43:665-669.

51. Pringle, A., and Taylor, J. W. 2002. The fitness of filamentous fungi.
Trends Microbiol. 10:474-481.

52. Probst, C., Njapau, H., and Cotty, P. J. 2007. Outbreak of an acute aflatoxicosis in Kenya in 2004: identification of the causal agent. Appl. Environ. Microbiol. 73:2762-2764.

53. Rustom, I. Y. S. 1997. Aflatoxin in food and feed: Occurrence, legislation and inactivation by physical methods. Food Chem. 59:57-67.

54. Schroeder, H. W., and Boller, R. A. 1973. Aflatoxin production of species and strains of the Aspergillus flavus group isolated from field crops. Appl. Microbiol. 25:885-889.

55. Scully, L. R., and Bidochka, M. J. 2005. Serial passage of the opportunistic pathogen Aspergillus flavus through an insect host yields decreased saprobic capacity. Can. J. Microbiol. 51:185-189.

56. Scully, L. R., and Bidochka, M. J. 2006. A cysteine/methionine auxotroph of the opportunistic fungus Aspergillus flavus is associated with hostrange restriction: A model for emerging diseases. Microbiology 152:223 232.

57. St. Leger, R. J., Screen, S. E., and Shams-Pirzadeh, B. 2000. Lack of host specialization in Aspergillus flavus. Appl. Environ. Microbiol. 66:320324 .

58. Stoloff, L., Van Egmond, H. P., and Park, D. L. 1991. Rationales for the establishment of limits and regulations for mycotoxins. Food Addit. Contam. 8:213-222.

59. Strauss, S. Y., Rudgers, J. A., Lau, J. A., and Irwin, R. E. 2002. Direct and ecological costs of resistance to herbivory. Trends Ecol. Evol. 17:278-285.

60. Torres, J., Guarro, J., Suarez, G., Suñe, N., Calvo, M. A., and Ramirez, C. 1980. Morphological changes in strains of Aspergillus flavus link ex fries and Aspergillus parasiticus speare related with aflatoxin production. Mycopathologia 72:171-174.

61. Wicklow, D. T., Bobell, J. R., and Palmquist, D. E. 2003. Effect of intraspecific competition by Aspergillus flavus on aflatoxin formation in suspended disc culture. Mycol. Res. 107:617-623.

62. Wicklow, D. T., and Horn, B. W. 2007. Association between vegetative compatibility and aflatoxin production by Aspergillus species during intraspecific competition. Mycoscience 48:267-273.

63. Wilkinson, H. H., and Ramaswamy, A. 2004. Increased conidiation associated with progression along the sterigmatocystin biosynthetic pathway. Mycologia 96:1190-1198. 